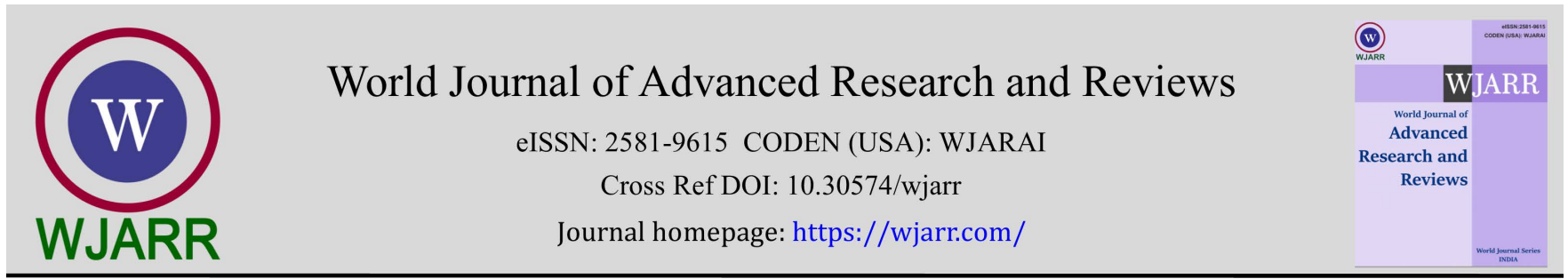

(RESEARCH ARTiClE)

Check for updates

\title{
Evaluation of indoor radon levels in Staff offices of Umm Al Qura University, Saudi Arabia
}

\author{
SHA ALLehyani ${ }^{1}$, RA Hassan $1,2,{ }^{*}$ and YM Bahashwan ${ }^{1}$ \\ ${ }^{1}$ Department of Physics, Faculty of Applied Sciences. Umm Al-Qura University, Makkah, Saudi Arabia. \\ 2 Department of Radiotherapy, National Cancer Institute, Cairo University, Cairo, Egypt.
}

World Journal of Advanced Research and Reviews, 2022, 13(01), 741-747

Publication history: Received on 25 December 2021; revised on 27 January 2022; accepted on 29 January 2022

Article DOI: https://doi.org/10.30574/wjarr.2022.13.1.0098

\begin{abstract}
Radiation is a natural part of the environment that people interact continuously, and radon is one of the most important sources because of its abundance and mobility. Due to gas form, radon can reach and accumulate in living places easily. Inhalation of radon and its progenies is an important risk factor for health hazards. Accurate measurement of radon levels is quite essential for the dose evaluation of radon exposure in buildings. In this present work, radon concentration was measured indoor 30 office in the College of applied Sciences/Umm Al-Qura University. Radon was measured with a portable Radon counter (Rad 7 detector, Durridge-USA), which was placed on the middle of office at a height of about $0.8 \mathrm{~m} .{ }^{222} \mathrm{Rn}$ gas levels were registered in $\mathrm{Bq} / \mathrm{m}^{3}$.

The measured concentration of radon in the air of office ranged from $14.2 \pm 5.68 \mathrm{~Bq} / \mathrm{m}^{3}$ to $23.9 \pm 7.52 \mathrm{~Bq} / \mathrm{m}^{3}$ with a mean of $18.96 \pm 8.3 \mathrm{~Bq} / \mathrm{m}^{3}$, while that of the progeny of radon varied from 0.00164 to $0.00266 \mathrm{WLM} \mathrm{Y}^{-1}$ (average: 0.00211). The mean indoor concentration of radon was considerably less than the lower levels prescribed by EEC 400 $\mathrm{Bq} / \mathrm{m}^{3}$, ICRP 200-600 Bq/m³ , NRPB $200 \mathrm{~Bq} / \mathrm{m}^{3}$, EPA $148 \mathrm{~Bq} / \mathrm{m}^{3}$, and WHO $100 \mathrm{~Bq} / \mathrm{m}^{3}$. The mean annual effective dose calculated $0.012 \mathrm{mSv} \mathrm{y}^{-1}$, which is less than the UNSCEAR and WHO recommended global lower average dose value of $1 \mathrm{mSv} / \mathrm{y}$. The hazard indices (PAEC, and CPPP) values were lower than the permissibility limit value.
\end{abstract}

Keywords: Indoor radon; Umm Al Qura University; Staff offices; Rad 7

\section{Introduction}

Naturally occurring radionuclides of terrestrial origin are present on the earth's crust since its origin. They are believed to have been produced when the matter of which the universe is formed first came into existence [1]. The spontaneous decay of the atom nucleus by emission of particles is called radioactivity, and is generally accompanied by electromagnetic radiation, natural radioactivity is displayed by various elements, there were probably many radioactive elements included in the mix of material that became the earth. Uranium-235, uranium-238, and thorium-232, three of this radioactive material, still survive to this day. Each of these elements has a half-life of billions of years, and each is at the top of the radioactive decay chain. All three natural decay chains contain radon isotopes. Radon-219, or "actinon", is an element in the uranium-235 chain, but we probably will never see actinon indoors because of its scarcity and short half-life. Radon-220, or "thoron", is a component of the thorium-232 chain. We will sometimes encounter thoron in indoor air, particularly near radon entry points, and, more often, in soil gas [2,3]. The Radon-222, or radon we are familiar with, is a byproduct of the uranium-238 decay chain (Figure 1). It can be found in indoor air, outdoor air, and soil gas, it is the first element in each decay chain not composed of a metal. Radon is, therefore, a noble, inert gas. This allows it to escape any chemical compound and diffuse into the air. Radiation exposure due to natural radionuclide's as well as high radon concentrations has been recognized in early seventies of the 20th century in building's closed spaces

\footnotetext{
${ }^{*}$ Corresponding author: RA Hassan

Department of Physics, Faculty of Applied Sciences. Umm Al-Qura University, Makkah, Saudi Arabia.

Copyright $(2022$ Author(s) retain the copyright of this article. This article is published under the terms of the Creative Commons Attribution Liscense 4.0.
} 
[4]. Around $90 \%$ of the indoor radon is due to cracks in the floor and wall, and the rest is due to building materials like gypsum board and monazite. [5].

The annual radon effective dose received by people is around $2.4 \mathrm{mSv}$, more than $50 \%$ of this contribution is from radon and its progenies [6].

Since 1998, radon and disintegration products have been considered human carcinogens (group 1) by the International Agency for Research on Cancer (IARC) of the World Health Organization (WHO) due to their known effects on the lung. Exposure to indoor radon is estimated to be the second cause of lung cancer after tobacco smoking [7-10].

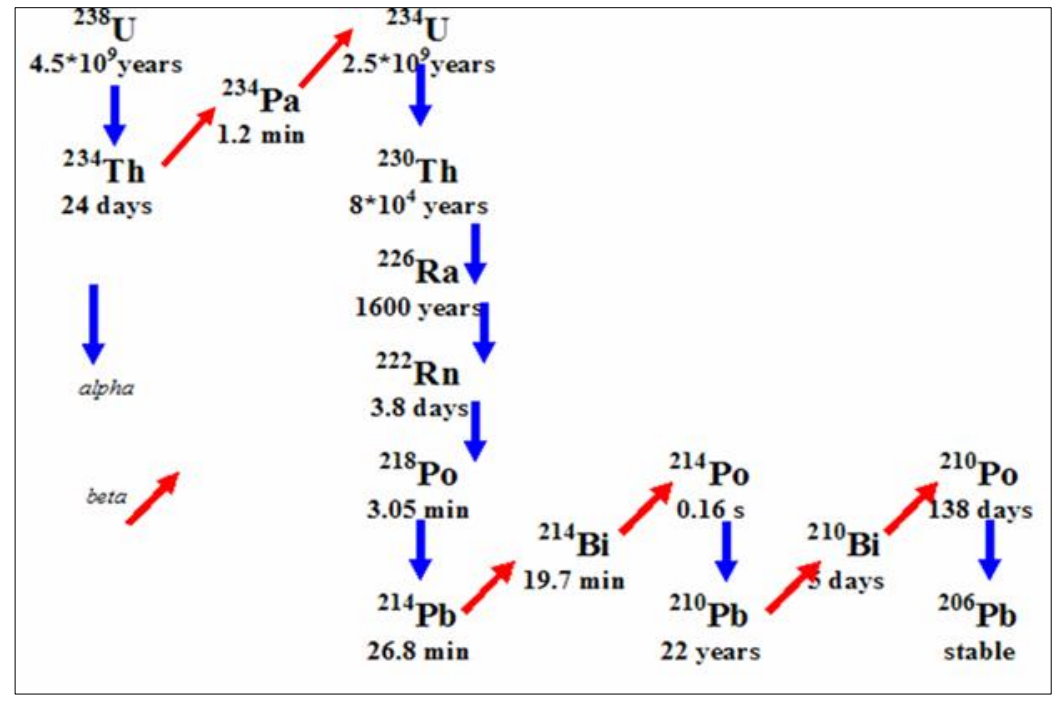

Figure 1 Uranium 238 decay chain

The risks of radon exposure at lower levels have also been examined in other research studies [11, 12]. Several studies have described other perceptions as well, and such as those presented by Cohen (1995), Becker (2004), Thompson et al. (2008), Dobrzy 'nski et al. (2018), or even Pylak et al. (2021), where the authors disagreed with the generalized opinion regarding low Radon levels and lung cancer. In Saudi Arabia, lung cancer is claiming more lives than ever before [18].

Being odorless and tasteless besides being invisible, there are two ways of radon measurement techniques. Active technique and Passive technique, active techniques can be defined as the technique that need power in order to be operated and are used normally for measuring the short term. Radon concentration can be measured by some of these active methods. Passive technique to evaluate Radon exposure on very long periods. Passive technique does not need power in order to be operated.

To evaluate the Ra-222 effects \& risks we need to calculate;

- $\quad$ The annual effective dose (AED) in units $\mathrm{mSv} / \mathrm{y}$ were calculated by using following equation [19]

$$
\operatorname{AED}(\mathrm{m} \mathrm{Sv} / \mathrm{y})=\mathrm{C}_{\mathrm{Rn}} * \mathrm{~F} * \mathrm{H} * \mathrm{~T} * \mathrm{D}
$$

Where, $\mathrm{C}_{\mathrm{Rn}}$ is the radon concentration in Bq. $\mathrm{m}^{-3}, \mathrm{~F}$ is the equilibrium factor, $\mathrm{F}=(0.4), \mathrm{H}$ : is the occupancy factor, $\mathrm{H}=$ (0.02) [20]. T: is the time in one year in hours, $\mathrm{T}=(8760 \mathrm{~h} / \mathrm{y}) . \mathrm{D}$ : is the dose conversion factor $\left[\mathrm{D}=9^{*} 10^{-6} \mathrm{~m} \mathrm{~Sv} /\left(\mathrm{Bq} \cdot \mathrm{h} \cdot \mathrm{m}^{-}\right.\right.$ 3)].

- $\quad$ Exposure to radon progeny (EP) in term of WLM Y-1 units were calculated using the following equation [21]:

$$
\mathrm{EP}\left(\mathrm{WLM} \mathrm{Y} \mathrm{Y}^{-1}\right)=8760 * \mathrm{n} * \mathrm{~F} * \mathrm{C}_{\mathrm{Rn}} / 170 * 3700
$$

$n$ : is the fraction of time spent staff offices $n=(0.02)$. Where the number of hours per year is $(8760)$ and is the number of hours per working month (170) [20]. 
- The assessment of exposure to $\mathrm{Rn}$ and its decay products must thus take account of the activity concentrations of the various alpha-emitters in the two series in the air that breathed. This thought, as well as the fact that it is the total alpha particle energy yet to be following, the decay of inhaled radionuclides that is important in determining dose, has led to the definition of radon exposure rate in terms of potential alpha energy concentration (PAEC) in units of working level (WL). The PAEC in units (WL) were calculated using the following equation [20-23]:

$$
\operatorname{PAEC}(\mathrm{WL})=\mathrm{F}^{*} \mathrm{C}_{\mathrm{Rn}} / 3700
$$

- $\quad$ The number of lung cancer cases per year per million people (CPPP) in each AED was calculated using a conversion factor of $18 \mathrm{mSv}^{-1} \mathrm{y}$, as recommended by the International Commission on Radiological Protection - ICRP (Quarto et al., 2015). CPPP was calculated using the following equation [24]:

$$
(C P P P)=A E D^{*}\left(18^{*} 10^{-6} \mathrm{mSV}^{-1} \cdot y\right)
$$

There was a great deal of researcher on indoor radon pollutions, most of the studies focused on the radon concentration measurements and effective dose estimations in residential buildings [25-30], indoor radon variations and its influencing factors [31-33]. As far as the research fields were concerned, most studies were carried out in residential environment, so the aim of this work to assessment radon levels at staff offices.

\section{Material and methods}

In order to conduct the current radon measurement survey, RAD7 detector was used (Figure 2 a, b). The RAD7 can detect radon concentration in the range of $0.1-20,000 \mathrm{pCi} / \mathrm{L}$ with the relative absolute accuracy of $\pm 5 \%$ [25].

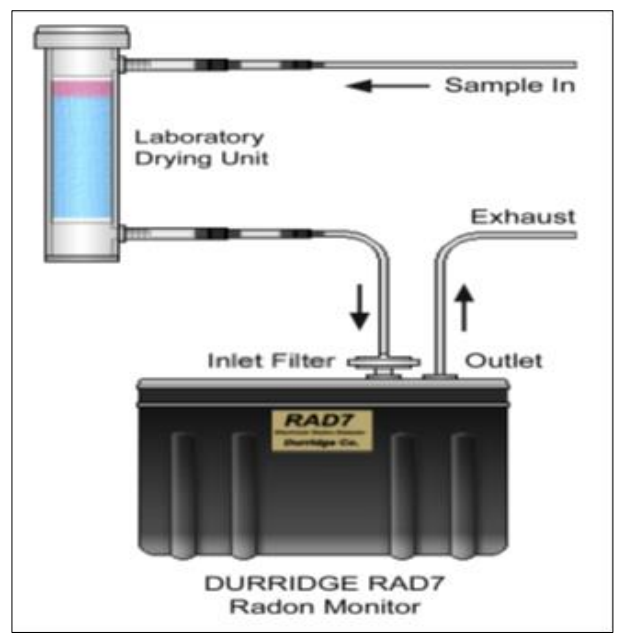

(a)

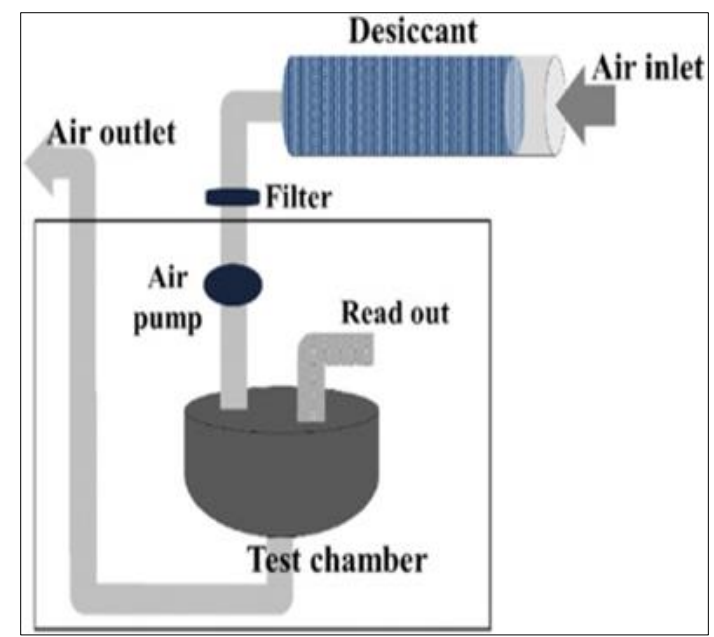

(b)

Figure 2 RAD7 Professional Electronic Radon Detector

The study was carried out at the staff offices of Umm Al Qura University- Saudi Arabia. The RAD7 able to make number of cycles measurement. Our measurements were made based on the U.S Environmental Protection Agency protocols [EPA 1992]. Before each measurement, the Rad 7 was purged more than 5 minutes to discharge the remaining radon gas including thorium inside the RAD7 using drying unit (desiccant is a granular $\mathrm{CaSO}^{4}$ ). After purging, the air inlet nozzle of the RAD7 was positioned $0.8 \mathrm{~m}$ above the floor, considering the breathing region of a setting student. The indoor radon concentration was continuously measured for with one day protocol $(0.5 \mathrm{hr}$. cycle, 48 recycle, auto mode, auto pump, thoron off), each measurement is done at the center of the office, there was some forced air-conditioning through ventilation in some offices, the entrance doors are mostly closed during the measurements. The measurement data were recorded and analyzed by using the program embedded already in RAD7. In addition, these devices measure and track additional environmental parameters above and beyond the radon concentration such as temperature, and relative humidity. 


\section{Results and discussion}

Radon assessments were carried out in 30 different staff offices, the mean, the maximum and minimum value of radon concentration were $18.96 \pm 8.3 \mathrm{~Bq} / \mathrm{m}^{3}, 23.9 \pm 7.52 \mathrm{~Bq} / \mathrm{m}^{3}, 14.2 \pm 5.68 \mathrm{~Bq} / \mathrm{m}^{3}$, respectively (table 1). The highest values were observed in the staff office $6\left(23.9 \mathrm{~Bq} / \mathrm{m}^{3}\right)$ which located at the ground level and where air ventilation was poor. Figure 3 shows the histogram of radon concentrations. As can be seen, all the measured values are below $148 \mathrm{~Bq} / \mathrm{m}^{3}$, which the recommended level issued by EPA. All values below $24 \mathrm{~Bq} / \mathrm{m}^{3}$. About $30 \%$ of offices exceeded the level of 20 $\mathrm{Bq} / \mathrm{m}^{3}$ and thus the high ventilation is recommended to reduce these levels. The use of a good ventilation system, or even taking advantage of natural air exchange by opening windows and doors on a regular basis, can help to prevent the accumulation of radon. Based on radon concentration and the time spent in an office, the AED due to exposure to radon and progenies were calculated (mean $0.012 \mathrm{mSv} / \mathrm{y}$ ). As stated in Tab.1 all the calculated values of annual effective dose were below the ICRP recommended level of $1 \mathrm{mSv}$ per year.

The highest value of EP was found in office 6 which was equal to 0.00266 WLM.Y-1, while the lowest value of EP was found in office 25 which was equal to 0.00164 WLM.Y $^{-1}$, with an average value 0.00211 WLM.Y-1. Which is lower than the recommended range 1-2 WLMY-1.

The highest value of PAEC was found in office 6 which was $0.00258 \mathrm{WL}$, while the lowest value of PAEC was found in office 25 which was $0.0016 \mathrm{WL}$ with an average value $0.00205 \mathrm{WL}$, which is less than the recommended value 0.0533 WL. Also, from Table-1, it can be noticed that the highest value of CPPP was found in office 6 which was equal to $2.7 \mathrm{x}$ $10^{-7}$, while the lowest value of CPPP was found in office 25 which was equal to $1.68 \times 10^{-7}$ with an average value $2.15 \mathrm{x}$ $10^{-7}$.

Table 1 Details of measured office radon concentrations and calculated annual effective dose

\begin{tabular}{|c|c|c|c|c|c|c|c|c|c|c|c|c|}
\hline Office & Floor & $\begin{array}{c}\text { Ventila } \\
\text { tion } \\
\text { Rate }\end{array}$ & $T(C)$ & RH (\%) & Mean & SD & High & Low & $\begin{array}{c}\text { AED (m } \\
\text { Sv } / y)\end{array}$ & $\begin{array}{c}\text { EP (WLM } \\
\left.Y^{\wedge}-1\right)\end{array}$ & $\begin{array}{c}\text { PAEC(W } \\
\text { L) }\end{array}$ & CPPP \\
\hline Office 1 & Ground & Low & 22.2 & 5.15 & 23.7 & 8.18 & 43 & 7.73 & 0.0149 & 0.002641 & 0.0026 & 2.7E-07 \\
\hline Office 2 & Ground & High & 22.3 & 4.17 & 21.1 & 6.54 & 40.3 & 5.37 & 0.0133 & 0.002351 & 0.0023 & $2.4 \mathrm{E}-07$ \\
\hline Office 3 & Ground & High & 20.3 & 4.75 & 19.6 & 7.65 & 37.5 & 0 & 0.0124 & 0.002184 & 0.0021 & 2.2E-07 \\
\hline Office 4 & Ground & High & 22.2 & 4.9 & 17.4 & 7.36 & 40.2 & 0 & 0.011 & 0.001939 & 0.0019 & $2 \mathrm{E}-07$ \\
\hline Office 5 & Ground & High & 20.1 & 3.12 & 18.2 & 6.97 & 40.3 & 5.36 & 0.0115 & 0.002028 & 0.002 & $2.1 \mathrm{E}-07$ \\
\hline Office 6 & Ground & Low & 20.1 & 5.11 & 23.9 & 7.52 & 34.8 & 5.6 & 0.0151 & 0.002663 & 0.0026 & 2.7E-07 \\
\hline Office 7 & Ground & High & 20.1 & 4.3 & 18.4 & 6.4 & 32.2 & 0 & 0.0116 & 0.00205 & 0.002 & $2.1 \mathrm{E}-07$ \\
\hline Office 8 & Ground & Medium & 23.5 & 3.5 & 18.8 & 10.4 & 37.5 & 0 & 0.0119 & 0.002095 & 0.002 & $2.1 \mathrm{E}-07$ \\
\hline Office 9 & Ground & Medium & 20.4 & 4.57 & 19.8 & 9.06 & 40 & 5.33 & 0.0125 & 0.002206 & 0.0021 & $2.2 \mathrm{E}-07$ \\
\hline Office 10 & Ground & Medium & 23.1 & 4.94 & 20.6 & 8.39 & 37.5 & 3.84 & 0.013 & 0.002295 & 0.0022 & $2.3 \mathrm{E}-07$ \\
\hline Office 11 & Ground & High & 23.4 & 4.44 & 18.3 & 6.77 & 27.8 & 1.17 & 0.0115 & 0.002039 & 0.002 & $2.1 \mathrm{E}-07$ \\
\hline Office 12 & Ground & High & 21.8 & 4.27 & 17.5 & 8.45 & 40.2 & 5.33 & 0.011 & 0.00195 & 0.0019 & $2 \mathrm{E}-07$ \\
\hline Office 13 & 1 & Medium & 24.6 & 4.27 & 22.7 & 6.9 & 34.7 & 0 & 0.0143 & 0.002529 & 0.0025 & $2.6 \mathrm{E}-07$ \\
\hline Office 14 & 1 & High & 23.2 & 3.42 & 17.9 & 6.84 & 28.4 & 4.39 & 0.0113 & 0.001994 & 0.0019 & $2 \mathrm{E}-07$ \\
\hline Office 15 & 1 & High & 18.5 & 4.19 & 16.4 & 6.42 & 43.71 & 0 & 0.0103 & 0.001827 & 0.0018 & $1.9 \mathrm{E}-07$ \\
\hline Office 16 & 1 & Medium & 27.4 & 5.4 & 16.4 & 6.93 & 34.73 & 3.89 & 0.0103 & 0.001827 & 0.0018 & $1.9 \mathrm{E}-07$ \\
\hline Office 17 & 1 & High & 23.1 & 4.4 & 15.9 & 8.65 & 31.8 & 0 & 0.01 & 0.001771 & 0.0017 & $1.8 \mathrm{E}-07$ \\
\hline Office 18 & 1 & Medium & 21.9 & 4.04 & 17.6 & 9.41 & 58.9 & 1.99 & 0.0111 & 0.001961 & 0.0019 & $2 \mathrm{E}-07$ \\
\hline Office 19 & 1 & High & 23.2 & 3.83 & 21.7 & 4.13 & 13.3 & 0 & 0.0137 & 0.002418 & 0.0023 & $2.5 \mathrm{E}-07$ \\
\hline
\end{tabular}


World Journal of Advanced Research and Reviews, 2022, 13(01), 741-747

\begin{tabular}{|l|c|c|c|c|c|c|c|c|c|c|c|c|}
\hline Office 20 & 1 & High & 23.1 & 4.19 & 16.9 & 10.8 & 44.6 & 4.6 & 0.0107 & 0.001883 & 0.0018 & $1.9 \mathrm{E}-07$ \\
\hline Office 21 & 1 & High & 22.7 & 3.9 & 18.6 & 20.6 & 28.8 & 3.56 & 0.0117 & 0.002072 & 0.002 & $2.1 \mathrm{E}-07$ \\
\hline Office 22 & 1 & High & 21.5 & 4.17 & 17.5 & 9.02 & 38.9 & 1.52 & 0.011 & 0.00195 & 0.0019 & $2 \mathrm{E}-07$ \\
\hline Office 23 & 1 & High & 22.5 & 3.17 & 19.6 & 8.78 & 33.5 & 3.78 & 0.0124 & 0.002184 & 0.0021 & $2.2 \mathrm{E}-07$ \\
\hline Office 24 & 1 & Medium & 23.6 & 5.24 & 21.2 & 7.83 & 40.3 & 5.13 & 0.0134 & 0.002362 & 0.0023 & $2.4 \mathrm{E}-07$ \\
\hline Office 25 & 2 & High & 22.6 & 3.57 & 14.8 & 5.68 & 46.5 & 2.45 & 0.0093 & 0.001649 & 0.0016 & $1.7 \mathrm{E}-07$ \\
\hline Office 26 & 2 & High & 25.6 & 4.86 & 16.9 & 6.11 & 35.7 & 0 & 0.0107 & 0.001883 & 0.0018 & $1.9 \mathrm{E}-07$ \\
\hline Office 27 & 2 & Medium & 24.5 & 5.22 & 17.1 & 9.42 & 38.6 & 3.2 & 0.0108 & 0.001905 & 0.0018 & $1.9 \mathrm{E}-07$ \\
\hline Office 28 & 2 & Medium & 22.3 & 3.72 & 19.7 & 10.24 & 34.3 & 1.34 & 0.0124 & 0.002195 & 0.0021 & $2.2 \mathrm{E}-07$ \\
\hline Office 29 & 2 & Low & 20.7 & 4.92 & 20.5 & 9.42 & 35.3 & 0 & 0.0129 & 0.002284 & 0.0022 & $2.3 \mathrm{E}-07$ \\
\hline Office 30 & 2 & Low & 22.1 & 4.97 & 20 & 8.31 & 47.1 & 2.89 & 0.0126 & 0.002228 & 0.0022 & $2.3 \mathrm{E}-07$ \\
\hline \multicolumn{3}{|l|}{ Average } & 22.42 & 4.3567 & 18.96 & 8.306 & 37.35 & 2.616 & 0.012 & 0.002112 & 0.002 & $2.2 \mathrm{E}-07$ \\
\hline
\end{tabular}

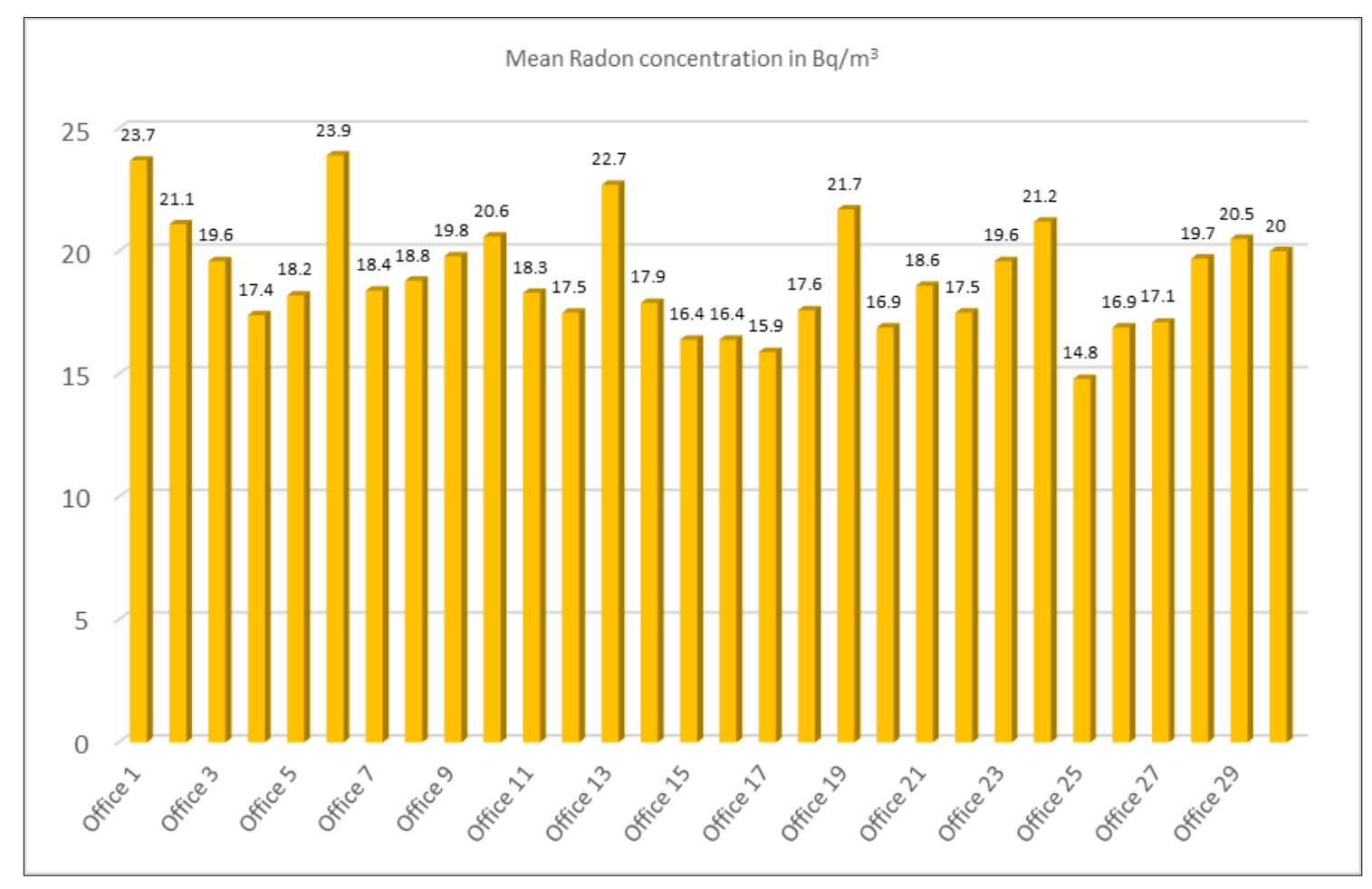

Figure 3 Mean Radon concentration in $\mathrm{Bq} / \mathrm{m}^{3}$

\section{Conclusions}

Long-term exposure to radon can increment the risk of lung cancer. In this manner, public awareness about adverse health effects of radon should be increased and systematic measuring strategies should be developed to identify locations where people are exposed to high levels of radon. In this study, staff office radon concentrations have been measured simultaneously based on the standard testing procedure. The most important finding was that using ventilation systems or even improving natural ventilation by opening the doors and windows can substantially reduce radon levels. This can be a cost-effective and temporary remedy for elevated radon levels; however, for sites with very high concentrations, remediation is recommended. 


\section{Compliance with ethical standards}

\section{Acknowledgments}

We would like to express our deep gratitude and thanks to our colleagues in Physics department, Faculty of Applied Sciences, Umm Al Qura University for their help and continuous encouragement.

\section{Disclosure of conflict of interest}

There is no conflict of interest.

\section{References}

[1] J Kebwaro, I Rathore, N Hashim, A Mustapha. Radiometric assessment of natural radioactivity levels around Mrima Hill, Kenya International Journal of the Physical Sciences. 2011; 6(13): 3105-3110.

[2] IAEA. Naturally occurring radioactive material (NORM VII) Vienna. 2015.

[3] Health Canada. Guide for Measurement in Public Buildings (Schools, Hospitals, Care Facilities, Detention centers), Canadian Minister of Health. 2008.

[4] D Popovic, D Todorovic. Radon Indoor Concentrations and Activity of Radionuclide's in Building Materials in Serbia" Physics, Chemistry and Technology. 2006; 4: 11- 20.

[5] Timothy MK. Geological Hazards: A Sourcebook, Greenwood Press. 2003.

[6] United Nations Scientific Committee on the Effects of Atomic Radiation (UNSCEAR) 1993 Report.

[7] World Health Organization. WHO Handbook on Indoor Radon; A Public Health Perspective World Health Organization: Geneva, Switzerland. 2009.

[8] Chen J. Lifetime lung cancer risks associated with indoor radon exposure based on various radon risk models for Canadian population Radiat. Prot. Dosim. 2016; 173: 252-258.

[9] ICRP. International Commission on Radiological Protection. Lung cancer risk from radon and progeny and statement on radon" Ann. ICRP. 2010; 40: 115.

[10] Darby S, Hill D, Deo H, Auvinen A, Barros-Dios JM, Baysson H, Bochicchio F, Falk R, Farchi S, Figueiras A, et al. Residential radon and lung cancer-Detailed results of a collaborative analysis of individual data on lung cancer in Europe" Scand .J. Work Environ. Health. 2006; 32: 1-84.

[11] National Research Council. Health effects of exposure to radon: BEIR VI. Washington, DC: National Academy Press. 1999.

[12] Lubin JA, Boice JD. Lung cancer risk from residential radon: Meta-analysis of eight epidemiological studies. J Nat Cancer Inst. 1997; 89: 49-57.

[13] Cohen BL. Test of the Linear-No Threshold Theory of Radiation Carcinogenesis for Inhaled Radon Decay Products. Health Phys. 1995; 68: 157-174.

[14] Becker K. One century of radon therapy. Int. J. Low Radiat. 2004; 1: 333.

[15] Thompson RE, Nelson DF, Popkin JH, Popkin Z. Case-control study of lung cancer risk from residential radon exposure in worcester county, massachusetts. Health Phys. 2008; 94: 228-241.

[16] Dobrzy 'nski L, Fornalski KW, Reszczy 'nska J. Meta-analysis of thirty-two case-control and two ecological radon studies of lung cancer. J. Radiat. Res. 2018; 59: 149-163.

[17] Pylak M, Fornalski KW, Reszczy 'nska J, et al. Analysis of Indoor Radon Data Using Bayesian, Random Binning, and Maximum Entropy Methods. Dose Response. 2021; 19: 15593258211009337.

[18] Saudi Ministry of Health. Guidelines on Lung Cancer for Health Workers. 2018.

[19] Hamidawi A. Radon and Thoron Concentrations Measurement in Al-Najaf and Al-Kufa Area PhD Thesis. Iraq: University of Baghdad. 2012. 
[20] UNSCEAR United Nations Scientific Committee on the Effects of Atomic Radiation: (2000) Sources and Effects of Ionizing Radiation, United Nations, New York. 2000.

[21] ICRP (International Commission on Radiological Protection Statement on Radon). 2009.

[22] Ismail AH, Jaafar MS. Indoor Radon concentration and its Health Risks in Selected Locations in Iraqi Kurdistan using CR- 39 NTDs" Bioinformatics and Biomedical Engineering (iCBBE), ldo 4th international Conference in Cheng du. 18-20 June 2010.

[23] Kansal S, Mehra R, Singh NP. Lifetime fatality risk assessment due to variation of indoor radon concentration in dwellings in western Haryana, India Appl Radiat Isot. Jul 2012; 70(7): 1110-2.

[24] Abdullah AA. Internal and external radiation exposure evaluation amongst selected workers and locations in Iraq Ph.D. Thesis, University Sains Malaysia, Malaysia. 2013.

[25] Durridge Company Inc. RAD7, Electronic Radon Detector User Manual. 2021.

[26] Environmental Protection Agency (U.S. EPA). Indoor Radon and Radon Decay Product Measurement Device Protocols, Office of Air and Radiation, U.S. EPA Publication, 1992, 402-R-92-004..

[27] Khan AJ. A study of indoor radon levels in Indian dwell- ings, influencing factors and lung cancer risks. Radiat Meas. 2000; 32(2): 87-92.

[28] Al-Jarallah MI, Fazal-ur-Rehman A-JF, Al-Shukri A. Indoor radon measurements in dwellings of four Saudi Arabian cities. Radiat Meas. 2003; 36(1-6): 445-448.

[29] Khayrat AH, Al-Jarallah MI, Fazal-Ur-Rehman X, Abu-Jarad F. Indoor radon survey in dwellings of some regions in Yemen. Radiat Meas. 2003; 36(1): 449-451.

[30] Papaefthymiou H, Mavroudis A, Kritidis P. Indoor radon levels and influencing factors in houses of Patras, Greece. J Environ Radioact. 2003; 66(3): 247-260.

[31] Rafique M, Rahman SU, Akram M. Estimation of concen- tration and exposure doses due to radon by using CR-39 plastic track detectors in the residences of Sudhnuti, Azad Kashmir, Pakistan. Environ Earth Sci. 2012; 66(4): $1225-1232$.

[32] Girault F, Perrier F. Estimating the importance of factors influencing the radon-222 flux from building walls. Sci Total Environ. 2012; 433: 247-263.

[33] Demoury C, Ielsch G, Hemon D, Laurent O, Laurier D, Clavel J, Guillevic J. A statistical evaluation of the influence of housing characteristics and geogenic radon potential on indoor radon concentrations in France. J Environ Radioact. 2013; 126(4): 216-225. 